\title{
Televisiones públicas para todos los públicos
}

\author{
Dr. Xosé Rúas Araújo \\ Profesor en la Facultad de Ciencias Sociales y de la Comunicación de Pontevedra \\ (Universidad de Vigo)
}

\section{RESUMEN}

El título de este artículo expresa la necesidad de que en los órganos de dirección de las televisiones públicas se acepte cierta representación social y no sólo política, sobre todo teniendo en cuenta que esta última responde a dudosos criterios de pluralismo, haciendo de las televisiones públicas un servicio a los gobernantes de turno, más que un servicio a todos los públicos, con unas garantías mínimas de acceso y control por parte de los mismos.

Además de analizar la situación en España y las distintas Comunidades Autónomas, se hace un repaso por la composición y normas por las que se rigen algunas de las televisiones públicas en el resto de Europa, finalizando con una reflexión sobre la indispensable búsqueda de una legitimación social dentro del vasto terreno audiovisual.

\begin{abstract}
The title of this article talks about the necesity that exists in the direction organs of the public televisions to be accepted a social representation, and no only political, because the last one answers to no clear reasons of pluralism, converting to the public televisions in a service to the governances, more than a service to all the publics, with guarantees to access and control.

This article also analyses the Spanish and communities situations, explaining the composition and rules of some publics televisions in the rest of Europe, finishing with a reflexion about imprescindible social legitimation in the audiovisual world.
\end{abstract}

Palabras claves: Televisiones Públicas/Comunicación/Audiovisual/Públicos/Europa/España/ Comunidades Autónomas.

Key words: Public Tv/Communication/Audiovisual/Public/Europe/Spain/Autonomous communities.

\section{Introducción}

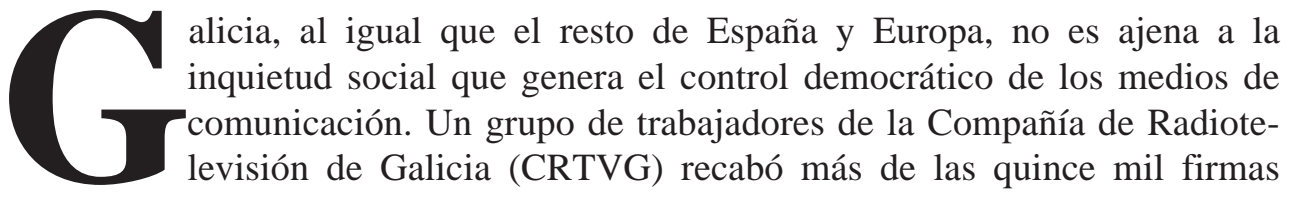


necesarias para la defensa de una iniciativa legislativa popular con el objetivo de que los sucesivos directores de la compañía sean elegidos directamente por el Parlamento gallego por mayoría de dos tercios y para un período de cinco años, evitando así que su designación y cese, que en la actualidad corresponde al presidente de la Xunta de Galicia, coincida con el cambio de Gobierno como consecuencia de la convocatoria de elecciones. De este modo, reclamaban que el procedimiento para su designación fuese similar al seguido en el caso del Defensor del Pueblo o las autoridades monetarias.

En su iniciativa, los trabajadores de la CRTVG criticaban el incumplimiento de los principios de programación establecidos en la Ley de Creación de la Compañía, así como la utilización partidista de la misma, recordando además la denuncia realizada por el Valedor do Pobo en uno de sus informes sobre el respeto al pluralismo político en los medios de comunicación públicos.

Por todo ello, "nos dirigimos a todas las personas con suficiente valentía cívica para ejercer sus derechos y a todas las instituciones democráticas de Galicia para que nos ayuden en este cometido", señalaban los promotores de esta iniciativa, que sería respaldada por todos los grupos de la oposición y, finalmente, rechazada por el Grupo Parlamentario del Partido Popular, mayoritario en la Cámara autonómica.

Como su propio nombre indica, se trataba de una iniciativa legislativa popular cuyo respaldo, ya acreditado por el mínimo de firmas necesarias para su defensa ante el pleno del Parlamento gallego, refleja las carencias por parte de los medios de comunicación públicos, tanto a nivel autonómico como estatal, en materia legislativa y de representación social, lo cual ha provocado un distanciamiento cada vez mayor de las televisiones y radios públicas de las exigencias de una sociedad plural.

Sin embargo, la fórmula planteada en esta iniciativa legislativa de vincular la designación de los directores generales de las televisiones y radios públicas al Parlamento no parece (a pesar de que indudablemente supondría una importante mejora sobre la situación de partida), la más adecuada, ya que, si bien garantiza el acceso y control de los grupos políticos más significativos a los medios públicos, no ocurre lo mismo con el acceso de los grupos sociales. Un acceso también citado expresamente en el texto de la Constitución y que la clase política, como depositaria de la confianza del pueblo, tampoco ha sabido defender. En este sentido, iniciativas como la de los trabajadores de la CRTVG corren el riesgo, tal y como ocurre en el caso italiano, de acabar politizando aún más el órgano que se pretendía despolitizar, por lo que habrá que buscar otras fórmulas y garantías de participación social y no sólo política en los medios de comunicación públicos.

Porque, como señala De Esteban, la naturaleza del poder político es siempre la misma, ya que el poder tiende a abusar del poder y la única diferencia entre las 
dictaduras y las democracias radica en que en éstas últimas existen controles democráticos para evitar dicho abuso. ${ }^{1}$

Un abuso que no es privativo de regímenes dictatoriales o totalitarios, pero que en los sistemas democráticos debe diferenciarse por el convencimiento de que sin un control realmente democrático no hay garantías, pues el político, tiene necesidad de propaganda más que de información. ${ }^{2} \quad \mathrm{Y}$ en la actualidad, los medios de comunicación, representan un instrumento decisivo para el ejercicio de la libertad y el control del poder político. Sin embargo, los gobernantes tienden a considerar que la información es un privilegio suyo que no tienen por qué compartir en muchos casos con nadie y, actuando así, ignoran o pretenden ignorar que el único depositario de la información es la sociedad, integrada por ciudadanos que son titulares del derecho fundamental a la información.

Por lo tanto, es necesario buscar el mejor camino para convenir que el problema esencial de una sociedad que quiere ser democrática radica en saber cómo son informados los ciudadanos y cómo deberían serlo, ${ }^{3}$ y perseguir, al mismo tiempo, un ejecutivo políticamente neutralizado, ${ }^{4}$ para que los medios de comunicación públicos puedan ejercer como administraciones neutrales y, en consecuencia, queden fuera del control del Gobierno.

Al mismo tiempo, algún autor incide en el hecho de que, a su juicio, "los medios parecen estar suplantando, querámoslo o no, la actividad política", y, además, se pregunta si los medios sustituyen a la política, aludiendo a la función de formación de la agenda que desempeñan en la construcción de la realidad social. ${ }^{5}$

Como tampoco se equivoca este autor al indicar, también, que los medios hacen política sin ser organizaciones políticas y sin contar con los partidos. Pero cuando concluye que el resultado es que, en un régimen de libertades plenas, la opinión editorial normalmente se impone por encima de lo que los partidos o las personalidades políticas quieran expresar, y además se queja de que la prensa en general está "cumpliendo algunas funciones propias del poder Ejecutivo", resulta fácil comprender que éste sea el juicio de un político y candidato presidencial del partido socialcristiano Copei a las elecciones de Venezuela.

Porque la pregunta de partida habría que plantearla al revés: ¿Sustituye la política a los medios?.

1 DE ESTEBAN, J.; 1997: "Los medios de comunicación como control del poder político", en Revista de Derecho Político, $\mathrm{n}^{\circ} 42$.

2 CHAMOUX; 1994: Droit de la communication. P.U.F., París.

3 SAUVY, A.; 1962: La naturaleza social. Taurus, Madrid.

4 SALA ARQUER, J.M.; 1984: "El Estado neutral. Contribución al estudio de las administraciones independientes", en Revista Española de Derecho Administrativo, nº 42.

5 FERNÁNDEZ, E.: 1996: “Medios de comunicación: ¿sustitutos de la actividad política?”, en Revista Contribuciones, $\mathrm{n}^{\circ} 2$. 
Sobre todo, teniendo en cuenta que los responsables de las radios y televisiones públicas son designados por los gobiernos de turno y que incluso algunos grupos de comunicación privados están inmersos en una dinámica de intereses recíprocos con el poder y gozan del favor de los gobernantes en el reparto de subvenciones y ayudas públicas.

Y la experiencia ha demostrado que nada ha cambiado en el control democrático de las televisiones y radios públicas en España durante los últimos veinte años, pese a que los dos partidos mayoritarios, han ejercido de gobierno y oposición. Además, recurriendo, incluso, a la posibilidad de vincular la designación de los responsables de las radios y televisiones públicas por una mayoría de $2 / 3$ del Parlamento se podría caer en un reparto de cadenas entre los principales partidos, como de hecho ha ocurrido en Italia, o una peligrosa complicidad entre gobernantes y medios de comunicación públicos, similar a la que se produce en el Reino Unido.

\section{Situación en España y las Comunidades Autónomas.}

Varios autores son los que hacen un análisis comparado de las distintas leyes autonómicas y sobre la televisión y la fórmula de designación de su respectivos directores generales, entrando también a analizar las funciones y limitaciones de sus consejos de administración.

González Pascual, por ejemplo, asegura que "la historia de las televisiones autonómicas en España es y ha sido la historia de un desatino", porque revela una "lucha despiadada por el control del medio televisivo" con la "disculpa de dotarse de un medio de difusión de sus propios valores culturales". ${ }^{6}$

Con frecuencia, se recuerda que todos los estatutos de autonomía de las Comunidades Autónomas recogieron la posibilidad de tener una televisión autonómica pero en cambio ninguna tuvo en cuenta las previsiones constitucionales y prácticamente todas copiaron el Estatuto de Autonomía de Cataluña, con la excepción de Euskadi, cuyo Estatuto de Gernika facultó a esta Comunidad Autónoma a crear su propia televisión, con independencia de lo estipulado en la Ley Reguladora del Tercer Canal de Televisión y el Estatuto de la Radio y la Televisión (en adelante, ERTV), que estableció un régimen de concesión de canales "de titularidad estatal" (nótese la matización) para el ámbito territorial de cada comunidad autónoma. Y también la ley vasca de radiodifusión, que asevera en su artículo 1 que la Comunidad Autónoma del País Vasco es "titular de los servicios de radiodifusión y televisión", lo cual originó un conflicto de competencias y creó una disparidad, también en alguna otra autonomía, entre canales autonómicos

6 GONZÁleZ PASCUAL, M.I.; 1999: "Las Televisiones Autonómicas, la historia de un desatino", en Revista Vasca de Administración Pública, n55. 
concedidos por el Gobierno central y canales no autorizados por este último pero puestos en marcha por la vía de hecho.

Destaca también, entre otros, el caso de Murcia y de la designación de los miembros del Consejo de Administración de la Radio Televisión de Madrid, así como los conflictos habidos por el intento de privatización de la Televisión Canaria.

Sin embargo, hay que hacer algunas precisiones más sobre el "desatino" en la creación y funcionamiento orgánico de las distintas televisiones autonómicas.

Así, Navarro de Luján, se refiere al régimen jurídico de las televisiones públicas en España, que impide, a diferencia e, incluso, en el sentido contrario de lo pretendido en la legislación de otros países, que una persona física o jurídica, pública o privada pueda emitir televisión sin obtener una concesión del Estado, por lo que cualquier otra práctica, aunque sea de hecho tolerada, se mueva en la más absoluta ilegalidad. ${ }^{7}$

Una implantación de las televisiones autonómicas que escapa de la esfera normativa de las Comunidades Autónomas, pues, si se analiza el artículo $1^{\circ}$ de la Ley 46/1983, de 26 de diciembre, Reguladora del Tercer Canal de Televisión, se observa que es el Estado quien crea un nuevo canal, cuya titularidad pertenece también al Estado y, además, se hace de acuerdo con lo dispuesto en el ERTV.

En consecuencia, la doctrina más aceptada es que el modelo establecido por la legislación española no ha producido los resultados pretendidos, puesto que ni ha asegurado la neutralidad de los medios públicos, ni tampoco su servicio al pluralismo social.

"Contando con la mayoría parlamentaria suficiente para gobernar, esta mayoría también se ve reflejada en la composición de la Comisión parlamentaria de control respectiva, lo cual enerva cualquier iniciativa que pudiera darse en orden a un control riguroso y efectivo de la televisión pública". ${ }^{8}$

Repasando las actas de las comisiones parlamentarias de control de RTVE y las distintas televisiones autonómicas, se podrá observar que la mayoría de los debates a los que da lugar la televisión pública en el Parlamento afectan a cuestiones como el tiempo de presencia en los informativos de los diferentes líderes políticos (del Gobierno y la oposición, se entiende) o el tratamiento que la televisión hace de los políticos de la oposición, sin que sea habitual encontrar debates profundos sobre los contenidos axiológicos de la programación o la presencia en pantalla de grupos sociales relevantes y de todas aquellas cuestiones que de verdad interesan al televidente y al ciudadano en general.

7 NAVARRO DE LUJÁN; 1997: “El modelo de Televisión Autonómica”, en Revista Valenciana D’Estudis Autonómics, $\mathrm{n}^{\circ} 19$.

8 Ibidem. 
Una demostración más de que se ha reducido el concepto de control público a lo estrictamente político, "de suerte que parece como si el principio de participación de los ciudadanos en las tareas públicas, que la Constitución reconoce, quedara limitado al ejercicio periódico del derecho de sufragio, sometiéndose tras ello al ciudadano a una especie de incapacitación cívica que dura el período que se prolongue la legislatura, hasta que sea llamado de nuevo a las urnas". ${ }^{9}$

También otro autor asegura que si hubiese que caracterizar en una sola nota el actual modelo jurídico de la televisión autonómica sería la de rigidez, pues se optó en su momento "por un modelo cerrado, hermético, que se basa en un sistema de concesión administrativa de la gestión de sólo un tercer canal de televisión y admitiendo únicamente su gestión directa tanto en el aspecto organizativo como en el mercantil". ${ }^{10}$

Una demostración más de que el ERTV deja escaso margen de autonomía real a las Comunidades Autónomas, creando un régimen que ratifica, en sus respectivos Estatutos de Autonomía (con la excepción antes mencionada del caso vasco), el modelo del canal estatal.

Este autor también defiende que la elección del director general de RTVE por un sistema de mayoría parlamentaria cualificada favorecería esa reclamada independencia, aunque se trata, a su juicio, de un requisito necesario pero no suficiente.

Desde el ámbito político, cabe recordar que el anterior secretario general del PSOE, Joaquín Almunia, presentó una propuesta electoral de modificación del sistema de designación del director general del Ente Público RTVE, que pasaría a ser elegido por el Congreso de los Diputados, una iniciativa que exigiría la modificación del vigente ERTV y que podría ampliarse a los nombramientos de todos los directores generales de las radiotelevisiones autonómicas.

Igualmente, Raúl Morodo, del Grupo Mixto, planteó una propuesta que pretendía extender el control parlamentario a todos los medios de comunicación social, sean o no públicos, que no prosperó, como tampoco salió adelante la propuesta del senador socialista Martín Retortillo de creación de un Consejo Independiente de RTVE de composición plural, con una composición de 15 miembros, 5 de los cuales serían elegidos entre personas de reconocido prestigio procedentes de los distintos ámbitos sociales, culturales e informativos de país, dos por los trabajadores de la radio y TV estatales, dos propuestos por el Gobierno y uno por el Defensor del Pueblo.

Una composición similar a la del Consejo recogido en la Constitución portuguesa de 1976, la denominada Alta Autoridad para la Comunicación Social,

9 Ibidem.

10 HIERRO, J.L.; 2000: "La evolución normativa", en Televisión y Desarrollo. Las Regiones en la Era Digital, Consejería de Educación de Extremadura. 
órgano compuesto por trece miembros, incluyendo a un magistrado designado por el Consejo Superior de la Magistratura, que lo presidirá.

Asimismo, en marzo de 1986, los grupos parlamentarios del PP y PSOE presentaron una proposición de ley que contemplaba la reforma del Estatuto de Radio y Televisión bajo el principio general de la ampliación de las competencias parlamentarias (velar por la programación, distribución de espacios a grupos sociales significativos, emitir informes y resoluciones, etc..) pero tampoco prosperó.

En este sentido, también se indica que a pesar de que la Ley del tercer Canal ha establecido un sistema unitario, el hecho de operar en un marco territorial y poblacional más reducido podría sugerir la apertura de cauces de participación y control más definidos y acordes, si bien finalmente no ha ocurrido así. ${ }^{11}$

Tan sólo destaca, en este sentido, la Televisión de Madrid, por ampliar la representación social de su Consejo Asesor y, además, porque su informe es preceptivo en todo lo relacionado con la programación. La murciana, por su parte, sigue un criterio de paridad sin establecer ninguna mayoría cualificada para su designación, si bien finalmente sus resoluciones se resuelven por voto ponderado.

Mención aparte merece el Consejo Audiovisual de Cataluña, que tiene encomendadas tareas de vigilancia y control, y que inicialmente quedó constituido por 13 miembros: 5 nombrados por la Generalitat, 4 por Parlamento y 4 por los municipios.

Sin embargo, posteriormente, la Ley 2/2000, de 4 de mayo, del Consejo del Audiovisual de Cataluña, ya indica, en su preámbulo, que "la experiencia lograda durante estos años del funcionamiento" de este organismo "ha revelado carencias que aconsejan su revisión”, por lo que el Parlamento de Cataluña decidió avanzar en el perfeccionamiento de "un órgano independiente con competencias reguladoras y sancionadoras". Y en el artículo 4 de esta ley, desarrollada en el Decreto 3/ 2001, de 28 de febrero, por el que se aprueba el estatuto orgánico y de funcionamiento del Consejo, se indica que este órgano estará integrado por diez miembros, nueve de los cuales serán elegidos por el Parlamento, a propuesta, como mínimo, de tres grupos parlamentarios, por una mayoría de dos tercios. El décimo miembro, que es su presidente o presidenta, será propuesto y nombrado por el Gobierno después de oír la opinión mayoritaria de los nueve miembros elegidos por el Parlamento. Es decir, que de nuevo estamos ante un órgano dependiente del Parlamento. Un órgano adecuado para el control de las radios y televisiones públicas, de amplias y ambiciosas competencias, pero que todavía podría ser perfeccionado en su composición, siguiendo el ejemplo alemán cuyas características expondré más adelante, para cumplir los ideales que asegura perseguir.

11 RODRÍGUEZ GARCÍA, J.A.; 1998: El Control de los medios de comunicación. Dykinson, Madrid. 
Por lo que respeta al ERTV, también otorga a las CC.AA. la posibilidad de crear un Consejo Asesor de RTVE en cada una de ellas, y establece, asimismo, que los consejos asesores deben ser consultados previa y preceptivamente por delegados territoriales sobre la programación y horario territorial.

Sin embargo, la posibilidad de someter estos consejos asesores al control parlamentario directo sólo se contempla en las leyes autonómicas de La Rioja y Madrid.

También el Grupo Parlamentario de CiU presentó en el Senado una proposición de ley, rechazada el 7 de octubre de 1997 por el pleno del Senado, para la creación de un Consejo Superior de los Medios Audiovisuales, con un miembro por cada Comunidad Autónoma, pero la respuesta fue que ya había un Comité Audiovisual de la Comisión del Mercado de las Telecomunicaciones, como si se tratase de aparatos más técnicos que políticos.

En el caso de Galicia, tanto los principios fundacionales como los de programación de la CRTVG como la Ley del Audiovisual de Galicia de 6 de junio de 1999 adolecen de garantías que permitan un adecuado control. De hecho, la Ley del Audiovisual de Galicia indica en su exposición de motivos que "es necesario articular mecanismos para que todos los gallegos puedan tener acceso a un sector audiovisual que favorezca el aumento y la mejora de sus capacidades y posibilidades de información y comunicación" y señala, entre sus principios generales, el "respeto al pluralismo político, religioso, social y cultural" de Galicia.

Sin embargo, también indica que corresponde "al Consello de la Xunta" la aprobación de los reglamentos necesarios para el desarrollo de la presente ley y "a la consellería competente" la ejecución de programas y acciones para el desarrollo del sector audiovisual, así como el control del cumplimiento de la normativa general del audiovisual en el ámbito de la Comunidad Autónoma de Galicia.

La ley gallega prevé la creación de un Consejo Asesor de las Telecomunicaciones y del Audiovisual de Galicia, que se configura "como un órgano de integración y participación de las instituciones, empresas, agentes y entidades directamente relacionadas con los referidos sectores, operadores y usuarios" y que "actuará con carácter consultivo y asesor para la administración y de mediación para el arbitraje y autocontrol entre los que voluntariamente se sometan a estos procedimientos". Este Consejo se considera "un mecanismo que impulsa la sociedad de Galicia" (cosa que, dicho sea de paso, no se puede decir que sea del todo cierta), "en la mejora y el prestigio del sector audiovisual", creando también una Comisión del Usuario.

Pero en el análisis de las diferentes cadenas autonómicas, también se recuerda, en concreto, que en el Consejo Asesor de Galicia su presidente es el presidente de la Xunta y su vicepresidente primero el conselleiro de Cultura, además de otros 
dos vicepresidentes más, "todos ellos -señala- cargos de designación política"12. Y hasta 19 se eleva también el número de representantes de las distintas consellerías de la Xunta. Incluso se recuerda que quien decide todos los nombramientos del Consejo Asesor de la CRTVG es el presidente de la Xunta, "de modo que el Ejecutivo gallego tiene asegurado el apoyo incondicional" de todos los órganos de este Consejo. ${ }^{13}$

Sobre el Decreto 276/1999, de 21 de octubre, que regula la composión y funciones del Consello Asesor de Telecomunicacións e Audiovisual de Galicia, ya queda claro, en su artículo $1^{\circ} .2$., que este órgano "se adscribe, sin perjuicio de su independencia funcional, a la Consellería de Cultura, Comunicación Social y Turismo" de la Xunta de Galicia, que será la encargada de "propiciar la cualificación y el autocontrol en relación con los contenidos de los medios de difusión audiovisuales específicos" del ámbito de la Comunidad Autónoma, pero siempre "en coordinación" con la Consellería de Cultura, cuyo máximo responsable también "queda facultado para dictar las normas necesarias para el desarrollo y la ejecución de este decreto", señala en una de sus disposiciones finales.

En España, el ERTV, aprobado por la Ley 4/1980, de 10 de enero, prevé dos tipos de control de los medios de comunicación social. Uno directo, que establece la creación de una comisión parlamentaria, pero de forma general y sin establecer el modo y se realiza a través de la formulación de preguntas. Se trata de un procedimiento rígido y limitado, que es una mala copia de la fórmula italiana, tal y como reconocen algunos autores.

Y otro es el indirecto, que se realiza a través del Consejo de Administración, integrado por 12 miembros de "relevantes méritos profesionales", algo que, desde luego, no se persigue con el mismo celo que en el caso del Reino Unido.

También el hecho de que el director general sea nombrado por el Gobierno rompe los principios de neutralidad e imparcialidad. Además, sólo caben dos pronunciamientos del Consejo de Administración ante su designación: o es favorable o se abstiene. Como en el referéndum que en tiempos convocó Franco para "verificar" el respaldo a su figura por el pueblo español.

Sin embargo, conviene destacar que el establecimiento como servicio público de los medios de comunicación supone una legitimación jurídica tanto para poder ejercer un control sobre su ordenación técnica como para garantizar el derecho de acceso a los mismos, concebido éste como la protección de los grupos que carecen de recursos suficientes para establecer sus propios medios.

"La función de inspección y control de un servicio público tiene como fin garantizar, por una parte, la exclusión de la gestión de la actividad de aquellos titulares que carecen de título para gestionarlo y, por otra, asegurar que el gestor

12 GONZÁLEZ PASCUAL. Op.cit.

13 Ibidem. 
concesionario de la actividad realiza ésta de acuerdo con las prescripciones contenidas en la concesión", lo cual justifica "la necesidad de creación de servicios u órganos especializados de control de las emisiones de los medios audiovisuales". ${ }^{14}$

Unos órganos de control que deben ser independientes del Gobierno para, precisamente, provocar una posición de alejamiento del Ejecutivo que garantice el pluralismo, como tampoco debe ser el Ejecutivo el que otorgue las concesiones (en prensa no ocurre así), sino una autoridad administrativa independiente compuesta por diferentes grupos y colectivos en que se vertebra cualquier sociedad democrática.

Pero lo cierto es que la doctrina más aceptada también sostiene que la alternancia en el poder de los distintos partidos ha reproducido, miméticamente, la tendencia de control por parte del Ejecutivo, por lo que sigue vigente la necesidad de garantizar el principio de independencia y participación, de acuerdo con el artículo 9.2. de la Constitución, mediante un órgano independiente del poder político.

Además, la propia Ley Orgánica de Libertad Sindical, por ejemplo, indica expresamente que los sindicatos deben acreditar la obtención de un diez por ciento o más del total de delegados de entre los miembros de comités de empresa y órganos dependientes de las Administraciones Públicas. De ahí la postura favorable a la creación de un órgano independiente para el control de los medios de comunicación públicos integrado, además de por representantes de los trabajadores, por miembros de organizaciones empresariales, colegios profesionales, organizaciones de consumidores y usuarios, el Defensor del Pueblo, etc.

Un Consejo que, en opinión de algunos autores, incluso debería otorgar y regular las ayudas a los medios de comunicación, disponiendo además de potestad sancionadora.

Sobre el contenido de la Constitución y demás legislación referida a los medios de comunicación, González Encinar recuerda que, legalmente, la televisión es en España un servicio público cuya titularidad se reserva al Estado, pero que admite dos modalidades de gestión: directa, por los gobiernos central y autonómicos, e indirecta, mediante concesión. ${ }^{15}$

Por lo tanto, toda la televisión en España se considera servicio público, pero no se explica en qué debe consistir exactamente. Además, en lo que se refiere a la independencia, objetividad e imparcialidad de las informaciones, la ley asegura exactamente lo contrario de lo que debería garantizar, pues no asegura la independencia, sino la dependencia de las televisiones públicas con respecto al Gobierno

14 RODRÍGUEZ GARCÍA. Op.cit.

15 GONZÁLEZ ENCINAR, J.J. (Ed.); 1996: La Televisión Pública en la Unión Europea. MCGraw-Hill, Monografía "Ciencias Jurídicas", Madrid. 
o comunidad autónoma en cuestión y, por tanto, el control partidista de las mismas, de modo que la televisión pública española no es libre frente al Gobierno del Estado y se convierte en una televisión gubernamental.

Un ejemplo de ello es el plan estratégico presentado en diciembre de 1994 por RTVE en el que se solicitaban mayores ayudas del Estado, una propuesta que, si bien podría servir para reducir la dependencia del mercado, también serviría para aumentar la dependencia del partido o partidos que habrían de consentir las subvenciones.

Asimismo, el artículo 149 de la Constitución establece que el Estado tiene competencias exclusivas sobre "normas básicas del régimen de prensa, radio y televisión y, en general, de todos los medios de comunicación social". También reconoce en su artículo 38 la libertad de empresa y la obligación de los poderes públicos, en el art. 9.2, de "facilitar la participación de todos los ciudadanos en la vida política, económica, cultural y social".

También Encinar critica que el Estatuto de la Radio y la Televisión de 1980 entienda simplemente por televisión la "técnica" de difusión, pero no entre en sus contenidos, limitándose a enumerar los posibles ("políticos, religiosos, culturales, educativos, artísticos, informativos, comerciales o publicitarios"), y olvidándose de regular las funciones de la televisión y estableciendo prohibiciones en vez de mandatos.

Las funciones de la televisión no están reguladas por ley, son sólo mencionadas en el Preámbulo de la Constitución y es por eso por lo que el Tribunal Constitucional entiende que, jurídicamente, al servicio público de la televisión no cabe exigirle un determinado contenido, con un criterio bien distinto al de otros países como Alemania.

Sin embargo, el hecho de que las funciones de la televisión pública no estén establecidas en la ley no debería ser óbice para que la televisión pueda desarrollar de manera satisfactoria su labor con garantía de independencia frente al Estado.

Por lo que respeta al Consejo de Administración de RTVE, está compuesto por doce miembros, elegidos para cada Legislatura, la mitad por el Congreso y la otra mitad por el Senado, mediante mayoría de 2/3 y, según dispone la ley, "entre personas de relevantes méritos profesionales". Su opinión no es vinculante y las competencias de director general abarcan desde el nombramiento del personal hasta la planificación y ordenación de la programación, pasando por las de orden económico y financiero. Políticamente, depende directamente del Gobierno, que lo nombra y cesa a su voluntad "oído el consejo de Administración".

La ley también prevé dos Consejos asesores de las sociedades gestoras, uno de RNE y otro de TVE, como órganos de apoyo al de Administración, encargados de emitir dictamen a solicitud de éste (es decir, tan siquiera por iniciativa propia), y que exista en cada Comunidad Autónoma un Consejo Asesor elegido por dicha 
autonomía que asiste al delegado territorial, si bien la mayoría de éstos tampoco se han constituido.

También se limita el campo de acción de las televisiones autonómicas a la emisión y transmisión de señales "a través de ondas", sin hablar de finalidad ni funcionalidad. Así, los terceros canales están organizados a imagen y semejanza de la TV pública central, pues sólo el País Vasco asume en su Estatuto competencias en medios de comunicación social. En España, aunque la ley lo permite, no existe, a diferencia de otros países, una tasa o canon de TV y, como los gastos siempre son superiores a los ingresos, recurren al endeudamiento, incrementando así su dependencia política.

Tan sólo la Ley General de Publicidad (Ley 34/1988 de 11 de noviembre), regula la forma en que ha de emitirse, los intervalos de tiempo que han de transcurrir entre la emisión de bloques publicitarios y el tiempo máximo por hora y día durante el cual puede emitirse publicidad, estableciendo también un sistema de controles y sanciones.

Por su parte, el Consejo de Administración tiene escasas posibilidades de control, al contrario de las amplísimas facultades que se conceden al Gobierno a través del ERTV, que también establece un único y escueto apartado referido al "control parlamentario directo", que prevé la constitución de una comisión parlamentaria en el Congreso de los Diputados.

En el Senado también existe una "Comisión especial sobre los contenidos televisivos" creada en 1993 y que publicó un informe proponiendo la creación de una "autoridad independiente", sin otra competencia que la de presentar "propuestas y recomendaciones" a la Administración.

Por todo ello, no son pocos los autores que observan que el Tribunal Constitucional español pretendía seguir en la línea del alemán, con muchos elementos tomados de la Ley Fundamental de Bonn, pero en la práctica no ha juzgado oportuno ni siquiera aproximarse en la línea del germano, limitándose a dar por buena la "reserva al Estado".

Así, se pueden observar sentencias contradictorias, unas diciendo que "el servicio público está en una especial relación de dependencia de los poderes públicos" y otra que ese mismo servicio público es una "garantía de la libre formación de la opinión pública". Sin embargo, ocurre que una información controlada por el Estado difícilmente puede ser libre frente al Estado.

De este modo se explica la consideración del ERTV, por parte de algún autor, como "inconstitucional", debido a toda una serie de razonamientos jurídico-constitucionales contradictorios y abstractos de los distintos preceptos constitucionales.

Como también se recuerda que la primera función de un partido político consiste en intentar convencer a los ciudadanos de que la opción política que representa es la mejor de las posibles y una televisión pública tiene exactamente la función contraria, no la de influir sobre la opinión en un sentido partidista ni 
de decantar las voluntades o votos en un determinado sentido, sino de mantener abierto el libre proceso de formación de la voluntad popular.

En este sentido, se indica que a un partido político no se le puede exigir que sea imparcial y cuando un partido político controla una televisión pública ésta se convierte, inevitablemente, en un instrumento de propaganda.

Y la doctrina más común también indica que lo que actualmente se produce en el campo de la televisión pública no es tanto una competencia entre distintas televisiones partidistas, cuanto una parcelación de las audiencias en función del ámbito geográfico y de color político de cada televisión.

De ahí la insistencia, una vez más, en la creación de una auténtica autoridad independiente a la que deben traspasarse buena parte de las funciones que en materia de televisión ejercen hoy los correspondientes gobiernos y que además permitiría aplicar, en mayor medida, el principio de la democracia participativa contemplado en la Constitución.

Y aunque el propio Encinar es citado por los trabajadores de la CRTVG para avalar su iniciativa legislativa popular, lo cierto es que este autor también asegura que "personalmente pienso que la televisión es un asunto demasiado serio como para dejarlo exclusivamente en manos de los partidos políticos" y, en este sentido, añade que "creo que estoy de acuerdo con la Constitución, o, dicho con otras palabras, que el dejar la televisión exclusivamente en manos de los partidos es lo que la Constitución, en tanto que Constitución democrática, prohíbe"16.

Con frecuencia se pone el ejemplo del Consejo de Administración de la televisión andaluza para criticar el hecho de haber sustituido a políticos por periodistas, asegurando que lo que se ha hecho es profesionalizar este órgano, pero mal. Sin embargo, lo oportuno sería que todos o al menos la mayoría de trabajadores de los medios de comunicación, autoridades y representantes sociales de los distintos ámbitos, tuviesen cabida en justa proporción, pues todos representan a la sociedad y a sus públicos, ampliamente entendidos ambos.

Además, el hecho de que España se defina como un Estado social y democrático de Derecho implica que la formación de la voluntad política debe hacerse en la sociedad antes que en el Estado y que debe realizarse de abajo arriba, de la sociedad a los poderes públicos.

Alejandro Perales, en su análisis sobre el marco jurídico de la televisión pública en España, recuerda que el ERTV incluye, dentro del servicio público, la "difusión de la cultura española y de sus nacionalidades y regiones", así como el "respeto al pluralismo social y lingüístico"17. Pero es que además este texto

16 GONZÁLEZ ENCINAR, ponencia pronunciada en el Centro de Estudios Constitucionales, en revista Cuadernos y Debates, $\mathrm{n}^{\circ}$ 55, Madrid, 1995.

17 PERALES, Alejandro, "El marco jurídico de la televisión pública en España", en AA.VV.; 1999: Jornadas de Consejos Asesores de RTVE, Parlamento de Andalucía, Sevilla. 
también reconoce, en su artículo 24, el derecho de acceso a la televisión de los grupos sociales y políticos más significativos. Y la Ley General para la Defensa de los Consumidores y Usuarios garantiza, en su artículo 17, la emisión en los medios públicos de programas dedicados a la información y formación de los ciudadanos, facilitando el acceso de asociaciones de consumidores y usuarios y otros grupos o sectores interesados. Además, el derecho de acceso también se recoge en algunos (no todos) de los diferentes textos legales de creación de las TV autonómicas.

En el mismo sentido se pronuncia López Escobar, al señalar la "carencia es España de una maquinaria concebida para la aplicación de controles normativos que protejan los valores que la televisión puede apoyar o minar". ${ }^{18}$

Este autor recuerda que en 1981 el Consejo de Administración de RTVE aprobó de forma unánime un conjunto de principios y pautas básicos a los que debe ceñirse la televisión, pero "no basta con aceptar estos principios de forma pasiva, sino que los medios deberán contribuir activamente a su promoción y defensa", al igual que el Estado. "España todavía no ha desarrollado un marco efectivo de control normativo", pues "muchos de los valores en cuestión se expresaron en forma de principios generales sin especificar obligaciones más definidas", señala López Escobar, quien también asegura que "la maquinaria de control normativo o es inexistente o está politizada y los consejos consultivos no fueron capaces de llenar este vacío de aplicación de normas".

No obstante, estamos ante un ejemplo más de la existencia de un malestar creciente en la sociedad que reclama, cada vez de forma más contundente, mejoras en la programación de la televisión, como es el caso de las asociaciones de televidentes, que en 1990 decidieron fundar una federación nacional, como una muestra más de que la sociedad empieza a tomar cartas en el asunto, al igual que ocurre con otro organismo español recientemente creado, el Consorcio Nacional de Asociaciones para una "televisión limpia".

Como también crece el número de ciudadanos que sienten que los consejos de administración de RTVE y las televisiones autonómicas han ejercido, principalmente, una función política y que, además, los legisladores mostraron un gran interés en cuestiones de tecnología de la televisión, pero muy poco en asuntos de programación.

Incluso en el ámbito de los propios medios de comunicación públicos, sus responsables señalan que se regularon las TV autonómicas sin haber promovido antes un amplio debate sobre este bien social.

Tal es el caso, por ejemplo, del que fue director general de Comunicación del Ministerio de Presidencia, José Ramón Pérez Ornia, quien recordaba que el Consejo de Administración de RTVE se ha convertido en un órgano político, pues

18 Ibidem. 
"de los 24 consejeros que ha tenido hasta la fecha, sólo uno fue elegido en calidad de independiente y de mutuo acuerdo entre los dos grupos parlamentarios mayoritarios; PP y PSOE". ${ }^{19}$

Al mismo tiempo, también afirmaba que "es obvio" que además de presencia política en el Consejo de Administración, debe procurarse la representación de los distintos sectores sociales en estos órganos y en los consejos asesores que, a su vez, podrían diversificarse atendiendo a los distintos géneros de programas y audiencias específicas. "El Consejo de Administración es un órgano casi decorativo que apenas tiene competencias ejecutivas, pues tan siquiera la aprobación de algo tan importante como los presupuestos del ente no es vinculante ni para el director general ni para el Gobierno", concluye en alusión a RTVE.

Además, hay que tener en cuenta que las pésimas relaciones entre el ente público RTVE y los dos canales autonómicos vasco y catalán estaban latentes en la redacción inicial del primer proyecto de ley reguladora del tercer canal, pues consideraban que creaba una dependencia inadmisible de la red de difusión de RTVE y era un competidor de audiencias en el mercado.

Sin embargo, parece una opinión dominante y compartida entre los estudiosos del fenómeno televisivo en España como entre sus responsables, que los terceros canales están en mejores condiciones que las cadenas estatales de RTVE de atender a sus audiencias específicas y de regirse por una estructura de programas que sean útiles a sus diversificados públicos, porque la cobertura no se refiere sólo al área geográfica territorial, sino sobre todo a los distintos grupos sociales que integran cada comunidad.

$\mathrm{Y}$ en este mismo sentido, en la cuarta reunión extraordinaria de la Conferencia general de la UNESCO, celebrada en París en 1982, ya se indicaba que la identidad cultural no puede ser fecunda ni auténtica si no se nutre de diversidades internas, asumidas en la comunidad armoniosa de las pertenencias y de las diferencias, de las costumbres y de las clases de vida y de los múltiples modos de expresión y de realización de la personalidad. Esta exigencia de pluralismo inherente a la identidad cultural se reafirma con fuerza en nuestra época en que en muchos países, industrializados o en desarrollo, minorías regionales, étnicas, religiosas o lingüísticas, así como numerosas comunidades de trabajadores inmigrantes, de exiliados o de refugiados, reivindican el derecho a vivir una identidad con múltiples raigambres.

Y con respecto a la Ley del Tercer Canal, da la impresión de que, más que regular los terceros canales, su objetivo es proteger a la televisión estatal ante la aparición de las autonómicas. Sobre todo si se analiza el contenido de su artículo 16, que establece que las sociedades concesionarias del tercer canal no podrán

19 PÉREZ ORNIA, J.R., "Hacia una alternativa del modelo de televisión del ente público RTVE", en AA.VV.; 1999: Jornadas de Consejos Asesores de RTVE, op.cit. pp.159-176. 
contratar en exclusiva la retransmisión de acontecimientos de interés nacional. Pero ¿cuáles lo son?. Prueba de lo anterior es, por ejemplo, el frecuente conflicto producido entre RTVE y la Federación Española de Fútbol para impedir la retransmisión de encuentros, atentando contra el principio de servicio público, o las polémicas y presiones desatadas, también en este sentido, cuando además entran en juego los intereses de las cadenas privadas y autonómicas.

Volviendo al aspecto referido al control de los medios de comunicación públicos, se recuerda que el legislador se ha limitado a cumplir con el mandato constitucional limitando este control a una de sus posibles fórmulas, la aludida expresamente por la Constitución, pero también se añade que esa alusión no excluye la posibilidad de otras, pues una cosa es el control parlamentario, directo o indirecto o ambos, como obligación constitucional y otra muy distinta que la Constitución excluya otras fórmulas ${ }^{20}$.

Algo que se expresa claramente con el principio de participación social, un derecho que se reconoce a todos los ciudadanos en nuestra Constitución en el artículo 9.2 y se concreta en el artículo 20.3, en el que se recoge la participación de los grupos en que se integran los ciudadanos en los órganos de control de los medios de comunicación.

De este modo, se está indicando que el titular de la soberanía, el pueblo, participa directamente o por medio de sus representantes, en los órganos de control de los medios de comunicación, y que esa participación se transforma también en una fuente de información para los poderes públicos que así tiene conocimiento directo de las demandas y necesidades de los ciudadanos en esta materia concreta. ¿Y sabe alguien cuáles son las deliberaciones o inquietudes plasmadas por los miembros de esa cueva obscura llamada Consejo de Administración de las televisiones públicas?, podríamos preguntarnos. Para responder, basta con observar los escasos pronunciamientos públicos de los mismos, a diferencia de otros países donde elaboran informes, en algunos casos preceptivos.

De hecho, Diego Carcedo, vocal del Consejo de Administración de RTVE, ponía de manifiesto el problema, al señalar ${ }^{21}$ que "el oscurantismo con el que se procesa la gestión es total. Yo soy miembro del Consejo de Administración y puedo decirles que carecemos en absoluto de información acerca de lo que se está haciendo, que se toman las decisiones sistemáticamente con la nocturnidad con la que ayer, por ejemplo, se produjo la venta de las acciones de Televisión Telemática en Vía Digital, que no fue consultada al Consejo de Administración".

La participación implica una conexión directa con el principio del pluralismo y, en consecuencia, a mayor participación social o ciudadana, nos acercamos

20 RODRÍGUEZ GARCÍA. Op.cit.

21 CARCEDO, Diego, "La RTVE como servicio público. Su financiación”, en AA.VV.; 1999: Jornadas de Consejos Asesores de RTVE, op.cit. pp.107-112. 
más a una democracia avanzada, donde el objetivo final del control democrático de los medios de comunicación es garantizar la libre formación y difusión de la opinión.

Y Enrique Gómez Reino, al analizar la problemática jurídico-constitucional de la TV, ponía de manifiesto lo que consideraba, al igual que la mayor parte de los autores antes citados, una contradicción constitucional entre el artículo 128.2 de la Constitución Española, que legitima la radio y TV como servicio público monopolizado, y el artículo 20.1, que reconoce y protege el derecho a expresar y difundir libremente ideas y opiniones mediante la palabra, escrito o "cualquier otro medio de reproducción" 22 .

En opinión de este autor, nuestro Tribunal Constitucional deja al arbitrio de los políticos la discusión, pues dice que la privada no está impuesta pero tampoco impedida. Es decir, que se trata de una opción política que va a depender de los gobernantes de turno.

Y si la justificación de la televisión como servicio público radica en la Constitución, no se entiende cómo el Tribunal Constitucional puede decir que la regulación de la televisión es una cuestión perteneciente a la discrecionalidad del legislador". ${ }^{23}$

En este sentido, también Muñoz Machado asegura que nuestro Tribunal Constitucional no supo poner coto a una inactividad legislativa que mermaba la plenitud del artículo 20.1. de la Constitución y "ha tardado mucho tiempo en aceptar que la paralización legislativa no puede respaldarse cuando hace imposible el ejercicio de derechos constitucionales" ${ }^{24}$, al contrario del rosario de sentencias que pueden observarse en el caso del Tribunal Constitucional Federal alemán.

Por lo tanto, no es de extrañar que algunos de los integrantes de los distintos consejos de administración de las televisiones reconozcan que las televisiones públicas son un premio que se otorga al que gane las elecciones. El problema está en que la denuncia siempre parte desde los representantes de la oposición y cuando están en la oposición, pero nunca desde el poder. Y así ocurre que la distancia entre las normas y los hechos es cada vez mayor en los medios de comunicación públicos y se incrementa la necesidad de satisfacer el interés de todos los públicos. Las circunstancias sociales y políticas en las que fue concebido el ERTV ya no son las mismas ni tampoco debería existir el mismo temor a la influencia que los medios de comunicación puedan ejercer sobre la opinión pública, como ocurría hace veinte años en España.

22 GÓMEZ REINO, E., “La problemática jurídico-constitucional en la televisión”, en AA.VV.; 1984: Jornadas sobre televisión autonómica, Diputación General de Aragón. pp. 97-110.

23 BASTIDA, F.J.; 1987: "Las televisiones regionales en España", en revusta Autonomies, nº.

24 MUÑOZ MACHADO, S., "La organización dual (pública y privada) de la televisión y sus problemas", en AA.VV.; 1995: El régimen jurídico de la televisión, Centro de Estudios Constitucionales, Colección "Cuadernos y Debates", no 55, Madrid, pp.29-49. 
Asimismo, Luis de Carreras, presidente del Consejo Superior de lo Audiovisual en TV3 de Cataluña, también recuerda que aún no hemos abierto un proceso constituyente con respecto a los medios de comunicación y eso quiere decir que estamos muy por detrás de los países más vecinos, como Portugal, Francia y el Reino Unido. "Todos los países de la UE, excepto España y Luxemburgo, tienen un Consejo Audiovisual, 24 países africanos tienen un consejo audiovisual. Hay 61 consejos audiovisuales en el mundo, incluidos países del antiguo Este de Europa. Estamos por detrás de la Historia. Estamos puramente en una situación de democracia formal", ${ }^{25}$ reiteraba este autor, quien también afirmaba que "se ha pasado del poder franquista sobre los medios al poder democrático sobre los medios" (un poder exclusivamente político, cabría añadir), pero "no se ha avanzado en las relaciones entre la sociedad y los medios de comunicación", añade. La única relación es la que marcan unos aparatitos instalados sobre los televisiones de algunos hogares en España, una relación tan técnica como la establecida por la ley española.

Asimismo, en las jornadas de Consejos Asesores de RTVE celebradas en Sevilla en marzo de 1999, se insistió en la necesidad, antes aludida, de constituir un Consejo Superior de Medios Audiovisuales como autoridad independiente, una propuesta que sigue paralizada en las Cortes y sobre la que los distintos políticos no logran ponerse de acuerdo.

Así, mientras el socialista Alfredo Pérez Rubalcaba indicaba que este organismo no podía nacer como resultado de la creación de una nueva dirección general de un ministerio, sino que su legitimidad debía quedar reforzada por el Parlamento, el portavoz del PP en la Comisión de Infraestructuras del Congreso, Cristóbal Pons, indicaba que la composición de este organismo debía ser el resultado de la matemática parlamentaria. Sin embargo, aquí está la raíz del problema, en esa vinculación que pretenden los políticos a una matemática estrictamente parlamentaria.

Por su parte, Victoria Camps Cervera, señalaba, en el citado encuentro, que "hace falta una autoridad independiente de los partidos políticos que vertebre esas quejas sociales, esas opiniones sociales que ahora no tienen cauce de expresión, porque el autocontrol sólo no sirve", asegura.

Pero volviendo a la idea de que la Ley del Tercer Canal reproduce los mismos principios que son de aplicación al ente RTVE, en cuanto al respeto al pluralismo político, religioso, social, cultural y lingüístico, hay que decir que esta crítica es muy repetida entre los distintos autores.

Como también lo es la denuncia de que las sociedades públicas concesionarias del Tercer Canal no puedan adquirir en exclusiva programas que impidan

25 CARRERAS, L., "La participación de la sociedad en la televisión pública", en AA.VV.; 1999:Jornadas de Consejos Asesores de RTVE, op.cit. pp.223-228. 
su proyección en un ámbito territorial distinto al de su propia comunidad y de que el ente público RTVE se reserve la prioridad en la retransmisión en directo de las competiciones o acontecimientos de ámbito internacional, aunque se establezca una excepción para el supuesto de que el acontecimiento tuviera un específico interés para una determinada comunidad autónoma.

En cualquier caso, lo cierto es que las sociedades concesionarias del Tercer Canal no podrán contratar en exclusiva la retransmisión de interés nacional.

Por lo tanto, la consideración anterior también debería ser recíproca con respecto a las televisiones autonómicas, permitiendo que los diferentes grupos sociales de la comunidad puedan expresarse e informar de sus legítimas aspiraciones y favoreciendo la búsqueda de nuevos espacios de representación televisiva.

"Los terceros canales no deben ser solamente televisiones de consenso político parlamentario, sino que deben expresar la pluralidad de las instancias y grupos sociales que no están representados políticamente", porque "la televisión no es sólo un medio económico y político, puede ser también el medio de intercambio de relaciones entre la sociedad política y la sociedad civil, entre poder central y local, entre productores y consumidores", indicaba Lorenzo Vilches en las citadas jornadas.

De ahí que las televisiones autonómicas se observen como las más indicadas para reunir y expresar los diferentes aspectos culturales, económicos y políticos de las Comunidades Autónomas, teniendo en cuenta, además, que el artículo 9.2. de la Constitución indica que la libertad no es tan sólo de los individuos, sino también de los "grupos sociales" en que se integra. Y en este sentido se niega la teoría del ciudadano como receptor pasivo, defendiendo la necesidad de propiciar un nuevo modo de criticar que solidifique el pluralismo y la tolerancia y desmitificando el concepto de comunicación de masas, según el cual la población no tiene otra participación y otro poder que el del consumo, es necesario hacer estallar la vieja noción de "público", anteponiendo a este concepto el de "públicos" que representan tendencias, gustos e intereses distintos.

Con respecto a los Consejos Asesores antes citados (que, como ya indiqué, no deben ser confundidos con los Consejos Asesores de RTVE en las Comunidades Autónomas, pues los Consejos Asesores recogidos en el artículo 9 del ERT son estatales y los del 14 autonómicos), varios son los autores que inciden en el hecho de que no se han creado en más de 20 años de vigencia del Estatuto, a pesar de que se trata de una figura clave (aunque desgraciadamente no vinculante) en el diseño de la participación social en los medios de comunicación.

$\mathrm{Al}$ referirse a los representantes de los Consejos, todos consideran necesaria la orientación de las televisiones públicas a la defensa de los intereses de los ciudadanos y el desarrollo del derecho de acceso como elemento específico y diferencial de la televisión pública, así como elemento legitimador de primer orden de cara a su existencia. 
Asimismo, citan la creación de Consejos Asesores "operativos", con competencias claras, capacidad de iniciativa y posibilidad de elaborar informes preceptivos en algunos temas, y formados por profesionales, expertos y teleespectadores.

Porque como indicó, en una de las citadas jornadas, uno de los representantes del Consejo Asesor de Galicia, Domingos Merino, "las conclusiones de las últimas reuniones no han servido absolutamente para nada" y "en RNE ni siquiera los boletines de desconexión territorial emiten en gallego".

Sin embargo, poco cabe esperar de una contestación como la de Urreiztieta Pérez, director del área de coordinación de centros territoriales de RTVE, quien, en las mismas jornadas, respondería posteriormente "al señor gallego", que "por primera vez los centros territoriales de TVE estamos haciendo un programa en directo de dos horas de duración, que se llama '¿Qué será?' y que es un programa hecho en gallego" por lo que concluye que "vamos a un respeto de un servicio público que yo creo que es una demanda de una región (sic) como Galicia, que tiene, además, su propia lengua".

En este sentido, es necesario destacar que uno de los escasos avances registrados en Galicia fue el convenio de colaboración firmado en 1998 entre la Xunta y el Ente Público de RTVE, en el que incluso se indica que la Comunidad Autónoma de Galicia "contribuirá" a la financiación del Centro Territorial de RTVE. Un acuerdo que en su exposición de motivos refleja una serie de finalidades que se corresponden con una obligación de RTVE y que, sin embargo, deberán costear los gallegos a razón de 225 millones de pesetas al año. Además, mediante este acuerdo, la Xunta se comprometió a pagar el 50\% de los gastos que se originasen por la emisión en directo para todo el Estado de acontecimientos de "interés especial" que se produzcan en Galicia y sólo se garantizaba la emisión en gallego de once de las quince horas semanales de emisión previstas.

\section{Un referente en Europa}

A continuación, se muestran diferentes modelos y formas de control de las televisiones públicas en varios países de la Unión Europea, con sus virtudes y defectos, porque incluso algunos de los aparentemente más ideales fallan luego en su aplicación práctica o no son trasladables a un contexto social como el nuestro, pues la evolución histórica de cada uno es la que ha concretado su plasmación.

Sin embargo, también es cierto que la mayor parte de ellos muestran un dinamismo que contrasta con el inmovilismo, legal y organizativo, de nuestras televisiones públicas, y sus experiencias en la búsqueda de un órgano de control independiente, aunque en ocasiones resulten fallidas o incompletas, siempre representarán un paso más que en España aún está por dar. En todo caso, algunas de las referencias siguientes servirán para poner en evidencia nuestras carencias.

Algún autor sostiene que las diferencias entre los países de la UE en este tema no tienen su base en el sistema constitucional ni en los correspondientes 
catálogos de derechos y libertades, sino en las distintas interpretaciones que se hacen de los mismos y del valor del pluralismo como principio democrático ${ }^{26}$. Así, concluye que, a pesar de sus limitaciones, el servicio de la BBC ha sido ejemplar y ha funcionado de modo aceptablemente democrático, aunque sus gobernadores sean elegidos por el Gobierno. Es decir, que se trata, más que nada, de una cuestión de voluntad.

Pero ahí está la evidencia de que "en España, todo, menos RTVE, ha cambiado", cuestión que pone de manifiesto con el ejemplo reciente de la "incapacidad política para cubrir cuatro vacantes en el Consejo de Administración de RTVE"27.

Por su parte, Pérez Ornia ${ }^{28}$ recuerda que en Francia hay una superabundancia legislativa que, sin embargo, no ha resuelto todos los problemas y que "en algunos casos se adoptaron medidas traumáticas, con una cirugía de hierro que ha dejado heridas que todavía no han cicatrizado", mientras que en Italia, al contrario de lo que sucede en Francia, juzga que "hay una gran parquedad y austeridad de leyes". Es decir, que una vez más estamos ante la confirmación de que la ausencia o abundancia de normas depende de los gobernantes de turno.

Rodríguez García ${ }^{29}$ distingue tres modelos de control: parlamentario (Italia), control de un órgano unipersonal independiente (EE.UU., Inglaterra y Francia) o por un órgano colegiado de participación también independiente (Alemania y Holanda).

Y estudiadas las ventajas e inconvenientes de unos y otros modelos, se inclina por un modelo de órgano colegiado de participación, formado por representantes de distintos sectores de la sociedad, más parecido al alemán que al holandés, desechando las soluciones del órgano administrativo unipersonal que, aunque teóricamente pueden garantizar tanto la independencia como la neutralidad, no responden a los principios de participación y de representación como expresión del pluralismo de la sociedad, de mayor autenticidad democrática.

Pero muchos son los autores que comparten la opinión de que, aunque el control parlamentario podría seguir cumpliendo su función de control de forma simultánea, por sí solo constituye un mecanismo insuficiente para garantizar el adecuado control democrático de los medios de comunicación públicos.

Y en este sentido, todos se muestran partidarios de la creación de un órgano independiente (que algún autor denomina "Consejo de la Comunicación"), que responda a los principios constitucionales de participación y representación, de un lado, y de cooperación con los grupos sociales, de otro, superando la actual

26 GONZÁLEZ ENCINAR. Op.cit.

27 Ibidem.

28 Op.cit.

29 Op.cit. 
regulación que limita ese control al parlamentario directo (comisión parlamentaria) o indirecto (el Consejo de Administración).

Porque se considera un error identificar democracia simplemente con el ejercicio por parte del poder, lo cual provoca una grave distorsión del sistema, al no garantizar el ejercicio del pluralismo político y degenerar en monismo informativo.

Pero pasemos a examinar las distintas formas de control de las televisiones públicas en Europa, aunque sin perder tampoco de vista que, a pesar de que en el propio Parlamento Europeo se observa cierta pretensión de creación de un órgano independiente, la Comisión Europea supedita la creación del Consejo Europeo de los Medios de Comunicación (que sólo tendría, en principio, carácter consultivo), a los diferentes estados miembros.

Como tampoco se puede obviar la crítica certera de Muñoz Machado ${ }^{30}$ a la directiva europea "Televisión sin Fronteras", del 3 de octubre de 1989, "por otorgarse competencias tan amplias en el dominio de la cultura como para imponer a los estados opciones de política legislativa, imponiendo reglas de preservación de valores culturales".

"Y lo sorprendente es que -añade también este catedrático- estas propuestas del legislador europeo no son combatidas con suficiente energía por aquellos gobiernos de los Estados miembros que ven gravemente amenazadas con estas iniciativas sus propias políticas en materia de audiovisual", como de hecho ocurre en el caso español.

\section{A. Italia}

En el sistema italiano, la vigilancia exclusiva corresponde al Parlamento. En Italia varios son los autores que se muestran de acuerdo en que el régimen jurídico de la radiotelevisión se ha desarrollado no tanto por el impulso legislativo como por el jurisprudencial, pues la Corte Constitucional ha puesto de manifiesto las insuficiencias normativas y la necesidad de elaborar una normativa general en materia de radiodifusión. Una situación que contrasta, como ya se indicó, con otros lugares donde el impulso ha venido dado como consecuencia de la presión social, más que por la propia iniciativa del legislador o las instituciones políticas.

Tanto el control como la dirección política de la radio y la televisión pública corresponde en Italia a una comisión parlamentaria y, en este sentido, esta parlamentarización del servicio ha sido objeto de críticas relacionadas con la desnaturalización del principio de separación de poderes y la atribución a un órgano de naturaleza parlamentaria de las facultades de un servicio público.

30 Op.cit. 
Esta comisión está compuesta por 40 miembros nombrados paritariamente por la Cámara de los Diputados y el Senado, oídos los distintos grupos parlamentarios, y dispone de amplias competencias, estableciendo lo que se consideró un auténtico "gobierno parlamentario del sistema radiotelevisivo", un fenómeno denominado "lottizzazione" o excesiva influencia de los partidos políticos y de sus exigencias sobre la información televisiva.

Algo sobre lo que se ha advertido que podría ocurrir en el caso de las televisiones y radios públicas estatales y autonómicas en nuestro país y que explicaría la necesidad de revisar la regulación de esta materia introduciendo una mayor presencia de personas de reconocida profesionalidad, por una parte, y de un mayor pluralismo que no quede reducido al ámbito político exclusivamente. ${ }^{31}$ Pero si los políticos controlan la prensa, ¿quién controla a los políticos?.

Los italianos disponen también de un Consejo de Usuarios, como órgano consultivo, y se creó un Comité Regional para los servicios radiotelevisivos, que regula el acceso a las transmisiones regionales programadas por la RAI (nótese la diferencia con RTVE) y formula propuestas a la RAI de contenido regional.

$\mathrm{Y}$ varios son los autores que también concluyen que el sistema italiano ha encontrado su veneno en el fenómeno del magnate Silvio Berlusconi, al trasladar las facultades de dirección de los medios al Parlamento, con lo que se pretendía reducir las facultades del Gobierno y hacer más transparente y controlable la gestión de la RAI. Sin embargo, este sistema ha chocado con la excesiva influencia de los partidos políticos. Sería necesario, por tanto, una autoridad administrativa independiente, pues se trata de un modelo que ha servido de copia a España, pero que en el caso español no garantiza los principios de independencia e imparcialidad, limitando además el principio de participación al ámbito exclusivo de la participación política.

Con frecuencia, en el análisis sobre la televisión pública en Italia se alude al Tribunal Constitucional italiano, para recordar que en 1976 declaró que el monopolio estatal de la radiotelevisión era inconstitucional, ya que contradecía los artículos de la Constitución que garantizan la libertad de manifestación del pensamiento y la libertad de iniciativa económica privada, dos enunciados, por tanto, de idéntico contenido a los recogidos en nuestra Carta Magna pero que dieron lugar a una interpretación bien distinta por nuestro Tribunal Constitucional. Como también se recuerda que una ley subordinó la RAI al Parlamento y, por tanto, a los partidos allí representados. Así, la crisis de la Comisión Parlamentaria de Radiotelevisión es consecuencia de la crisis general de los partidos políticos italianos. Una comisión que tampoco está en situación de desarrollar aquella función de dirección general que hubiera debido caracterizarla, pero que en rea-

31 RODRÍGUEZ GARCÍA. Op.cit. 
lidad nunca ha desempeñado plena y eficazmente, puesto que el aspecto partidista prevalece sobre el institucional.

La RAI es una sociedad anónima calificada de "interés nacional" que gestiona el servicio como consecuencia de una concesión acordada en Consejo de Ministros y otorgada por el Presidente de la República, confirmada recientemente por otros veinte años.

El nombramiento de los 16 miembros de su Consejo de Administración se atribuyó en exclusiva, como consecuencia de la ley antes citada, a la Comisión Parlamentaria para la Dirección y la Vigilancia de los Servicios de la Radiotelevisión. Sin embargo, el dominio de los partidos políticos sobre la RAI llevó en pocos años a un auténtico reparto de las cadenas y de los puestos de responsabilidad.

Posteriormente, se ha previsto un Consejo de Administración de sólo cinco miembros nombrados por los dos presidentes de las Cámaras.

Pero el éxito de los partidos de centro-derecha en marzo de 1994 y el consiguiente nombramiento como presidente del Consejo de Ministros del diputado Silvio Berlusconi, propietario del grupo Fininvest, el competidor de la RAI, provocó la dimisión de los cinco administradores y del director general, que pasaron a ser sustituidos por otros elegidos por los nuevos presidentes de las dos Cámaras, modificando sustancialmente los contenidos de la RAI. Un peligro, el de la "berlusconización", que amenaza a cualquier televisión o radio pública cuya organización dependa exclusivamente de la matemática parlamentaria.

Destacar también que la concesionaria de la RAI tiene la obligación de efectuar transmisiones radiofónicas y televisivas en lengua alemana y "ladina" para la provincia de Bolzano, en lengua francesa para la Región Autónoma del Valle de Aosta y en lengua eslovena para la Región Autónoma del Friuli. Se financia, al igual que otras televisiones públicas europeas, por el canon de abono, que en el caso italiano tiene naturaleza tributaria y es un verdadero impuesto. El usuario debe pagar el canon por la mera tenencia de aparatos aptos o adaptables para la recepción de transmisiones radiotelevisivas, sea cual sea el uso que haga de ellos.

En este sentido, algunos autores sostienen que sólo una televisión pública adecuadamente financiada con el canon de abono puede estar en situación de no sufrir el chantaje de la posible pérdida de audiencia.

Los ingresos publicitarios son considerados por la ley como "fuentes accesorias" de las rentas de la RAI. La publicidad tiene, de todas formas, un límite horario establecido, y se fija también el de las privadas.

Con respecto al Consejo Consultivo de los Usuarios, este órgano desempeña una función consultiva para la tutela de los intereses de los sectores más débiles de los usuarios frente a todos los medios de comunicación televisiva, votando resoluciones en las cuales se censuran episodios de malos hábitos televisivos, 
ejerciendo así una función que se superpone con las competencias de la Comisión Parlamentaria, si bien se indica que los controles parlamentarios no deberían interferir en la gestión cotidiana del servicio público, que es otro de los peligros de esta vinculación, ya que no se puede esperar a que el Parlamento se pronuncie con la celeridad que requiere la gestión diaria de la televisión y radio públicas italianas.

Los italianos fueron llamados el 11 de junio de 1995 a expresar su propio voto en cuatro referéndums abrogatorios en materia de radiotelevisión y votaron sí a la posibilidad de privatizar parcialmente la RAI, algo que se interpretó como una consecuencia de la pérdida de desprestigio que el grupo Berlusconi ha influido sobre la RAI.

Una pérdida de prestigio que el profesor de la Universidad de Salerno, Gianpietro Mazzoleni, vincula a la incapacidad de los legisladores para llegar a una solución de compromiso sobre los puntos más delicados de la disputa, lo cual permitió que los protagonistas del negocio de la televisión fijaran sus propias reglas de juego durante muchos años ${ }^{32}$.

De hecho, durante dos décadas, la imagen de la RAI fue identificada con la de una madre (la "Mamma") que ha nutrido a generaciones de italianos e incluso se llegó a decir que la unidad nacional italiana se debía más a la televisión que a las guerras de independencia del siglo XIX, aunque también indica que en el diseño en Italia de la radio y televisión públicas influyó el patrón cultural de la vida sociopolítica italiana, su doble moralidad y, por tanto, falta de identificación de valores.

En el caso italiano, destaca la figura del Garante como responsable de aplicar las disposiciones relevantes de la Ley de Televisión de 1990, que en la actualidad es un magistrado y dispone de un organismo de asesoría: el Consejo Nacional de Televidentes.

\section{B. Alemania}

En el caso alemán, el Tribunal Constitucional Federal (en adelante, TCF) impone como condición la participación de todas las tendencias importantes de la sociedad, de todas las fuerzas sociales relevantes. Mediante una sentencia, el TCF llegó a concretar que la radiodifusión es "asunto de la colectividad" y debe contener exigencias de tipo representativo y de participación social que sean reflejo del pluralismo interno. Esta participación se ha plasmado en las distintas leyes de los Lander de una forma amplia, pues están representados los más importantes grupos ideológicos y sociales en los máximos órganos de control.

El TCF también señala, en otra sentencia, que las televisiones públicas deben cubrir las necesidades generales de la población, e impone que la regulación de las emisoras privadas se haga de modo que su concesión se acuerde por

32 MAZZOLENI, G., “Existe un problema de valores vulnerables en Italia?”, en BLUMLER, G.J.; 1993: Televisión e interés público, Bosch, Barcelona, pp.11-130 
autoridades independientes, es decir, fuera del control de los representantes políticos. Porque, precisamente, si son políticos, ¿cómo iban a garantizar la independencia de los órganos que gestionan?.

En Alemania, la radiodifusión se configura, por tanto, como un servicio público cuyo control será ejercido por la sociedad para garantizar la independencia de la radiodifusión frente al Estado.

Alemania dispone de un Consejo de Televisión compuesto por 66 miembros, con representantes de los distintos lander, representantes de las distintas confesiones religiosas, sindicatos y empresarios, además de miembros de las asociaciones de agricultores, artesanos, editores de periódicos, periodistas, representantes de asociaciones deportivas, culturales, etc., entre cuyas funciones está la de asesorar en la configuración de la programación. En el Consejo de Radiodifusión participan grupos políticos, ideológicos y sociales y se establece un límite al número de representantes enviados por el Gobierno, Parlamento y Senado, que no podrá exceder de un tercio del total de sus miembros.

En cuanto al Consejo de Administración está compuesto por nueve miembros, de los cuales siete son elegidos por el Consejo de Radiodifusión y los otros dos por el Comité de Personal, para un mandato de seis años.

Con respecto al caso alemán, ocurre que la pluralidad de agrupaciones y colectivos representados en los órganos de control de la radiodifusión pública y privada hace posible garantizar el derecho de libertad de conciencia, esto es, el derecho a formar la propia conciencia y el propio pensamiento, mediante un modelo de pluralismo interno.

Y la representación de los distintos grupos sociales en el Consejo de Radiodifusión se concibe no tanto como un modo de garantizar los intereses del grupo en sí mismo, sino que la misión que éstos tienen encomendada es la de velar por el interés general.

En estos consejos existe participación gubernamental y parlamentaria, pero ésta es limitada para evitar, como señala la jurisprudencia del TCF, que la radiodifusión pueda dejarse en manos del Estado, ya que se trata de un asunto de la colectividad o sociedad alemana.

Un modelo bastante próximo a lo manifestado en el artículo 20.3 de nuestra Constitución, en relación con la participación de los grupos políticos y sociales en unos medios de comunicación que no están controlados por el Estado ni el Parlamento, sino por la sociedad.

También al analizar el papel de la televisión pública en Alemania, algunos autores $^{33}$ recuerdan que, en Alemania, la televisión pública se orienta en la tradición

33 WOLFGANG HOFFMANN-RIEM, WOLFGANG SCHULZ, "La televisión pública en Alemania", en GONZÁleZ ENCINAR, JJ. (Ed.); 1996: La Televisión Pública en la Unión Europea, McGraw-Hill, Monografía "Ciencias Jurídicas”, Madrid, pp. 59-88. 
del "public service" y, por tanto, exige una organización libre frente al Estado.

En este sentido, afirman que la experiencia del nacionalsocialismo dejó muy claro en Alemania que la televisión no debe ser utilizada como un instrumento de influencia o de propaganda del Estado, cosa que, por cierto, no parece haber ocurrido tras los cuarenta años de dictadura en España.

Para garantizar la libertad de la televisión frente al Estado, las televisiones deben tener su propia organización independiente de aquél. La financiación tampoco se hace a través de los presupuestos Generales del Estado, sino, principalmente, a través del canon de televisión.

La televisión alemana, también como consecuencia del nacionalsocialismo, está hoy organizada de forma federal. Se ha querido impedir así que se concentre en el poder central (Federación) toda la fuerza que la televisión otorga y, por tanto, la Federación es sólo competente en materia de emisiones dirigidas al extranjero.

La vinculación de la televisión con la sociedad se consigue mediante un sistema de control de pluralismo interno, a través del Consejo de Televisión, el órgano encargado de integrar distintas perspectivas de fuerzas, intereses y grupos sociales.

Así, la representación social garantiza la fragmentación de la programación para distintos públicos.

Los miembros del Consejo pertenecen a asociaciones económicas, culturales y de otros ámbitos, pero están obligados a actuar como representantes de la sociedad en su conjunto y no como representantes de unos determinados intereses.

El legislador también dispone de un margen de discrecionalidad relativamente amplio para determinar los grupos que pueden enviar un representante al Consejo, un ejemplo que en el caso español no se ha contemplado, en la práctica, con el mismo afán.

Este Consejo tiene competencias para participar en las decisiones relativas a programación, en la elaboración del plan económico-financiero y en las decisiones sobre personal, si bien su decisión más importante es el nombramiento del Intendente.

Con respecto al Consejo de Administración, sus miembros son designados por el Consejo de Televisión, pero en menor número, lo cual le otorga gran operatividad, aunque sin perder capacidad de control por parte de los integrantes del primero.

La televisión requiere en Alemania una organización libre frente al Estado, lo cual significa que el Estado no puede ni gestionar directamente la televisión ni influir sobre el contenido de la programación, además de recordar que el Tribunal Constitucional estimó que ese control estatal sólo puede ser limitado y con carácter subsidiario, es decir, un control jurídico en sentido estricto.

La jurisprudencia del TCF alemán pone de manifiesto que éste ve en la televisión pública una garantía de que continúa orientada a la libertad de forma- 
ción de la opinión de todos los ciudadanos. De hecho, "si Alemania se distingue por el relativo cuidado y consideración para con los intereses de sus canales públicos, puede que se explique, en parte, por el hecho de que las decisiones clave fueron tomadas no por políticos partidistas, sino por jueces del Tribunal Federal Constitucional", indican los profesores de la Universidad de Hamburgo.

El desarrollo de la televisión en Alemania Occidental ha sido profundamente marcado por la jurisprudencia del TCF, tras una serie de contenciosos fundamentales relativos a la estructura televisiva que han ido estableciendo ciertas directrices esenciales del orden televisivo.

El Tribunal ha fundamentado sus decisiones en un mandato, inherente al derecho básico de libertad de comunicación (artículo 5 de la Ley Fundamental), según el cual la legislación debe especificar la estructura del ordenamiento televisivo mediante leyes. Y estas leyes deben asegurar la libre formación de la opinión pública e individual en sentido amplio, es decir, no limitarse a la simple cobertura informativa, sino abarcar también la transmisión de informaciones y opiniones de todo tipo.

Además de la libertad para expresar opiniones y alegatos de hecho, también se considera importante la libertad de los receptores para informarse exhaustivamente.

En suma, la libertad televisiva está al servicio de la libertad para formar opiniones. Y, en líneas generales, el sistema legal protege de agresiones a una serie amplia de valores sociales.

El Tribunal Federal Constitucional también ha subrayado repetidamente que la diversidad no es una categoría puramente cuantitativa, excluyendo al poder de cualquier posible influencia sobre la formación de opinión.

Por ello, tanto el Consejo de Radio y Televisión como el Consejo de Administración están compuestos por representantes de una serie de fuerzas y grupos sociales cuya variedad interna tiene por objetivo impedir que un elemento singular ejerza influencias unilaterales.

En este sentido, se entiende que las normas por sí solas no bastan para obtener los resultados deseados, sino que también es necesario garantizar su aplicación. Una afirmación que bien podría tenerse en cuenta a la hora de analizar la situación de las radios y televisiones públicas estatales y autonómicas en el caso de España.

Y aunque se reconoce que los partidos políticos han logrado hacerse con un papel decisivamente influyente en la composición de estos órganos y que hubo muchos problemas, también se indica que, pese a todo, el sistema compensatorio de verificaciones y balances (check and balances) entre las diferentes fuerzas ha surtido efectos positivos, las minorías siguen siendo atendidas por la televisión pública y la transmisión de programas culturales y políticos de alta calidad es muy frecuente. 


\section{Francia}

En Francia existe una Comisión Nacional de la Comunicación y de las Libertades (CNCL), compuesta por trece miembros, tres de los cuales son cualificadas personalidades procedentes del sector audiovisual, de las comunicaciones, y una tercera de la prensa escrita. Este órgano también tiene la atribución de la gestión de frecuencias y la responsabilidad de designar las personalidades cualificadas de los Consejos de Administración de los medios de comunicación públi$\cos$, en concreto, cuatro de sus doce miembros, e incluso puede sancionar a medios privados que no cumplen las condiciones de las concesiones, además de elaborar un informe periódico sobre su actividad que envía al Parlamento.

Asimismo, el Consejo Superior de lo Audiovisual (en adelante, CSA) es el órgano fundamental sobre el que gira todo el sistema audiovisual francés, si bien algunos autores critican que sólo se traduzca en una participación política, por lo que se considera que debería nutrirse de la aportación alemana.

El de Francia es un modelo propio de un país centralizado, mientras que en Gran Bretaña, por el contrario, la BBC dispone de estaciones nacionales regionales para Irlanda del Norte, País de Gales y Escocia. Francia ha vivido una constante reforma legislativa en materia televisiva, tratando de preservar, en todo momento, el papel central del Estado.

Con respecto al CSA, se indica que podía tener mayores poderes y también se recuerda que tiene la potestad de ejercer el control sobre los operadores privados para indicar que el sector público no es, por tanto, el único que está vinculado por el interés general.

En todo caso, parece que la existencia de una autoridad administrativa independiente ha permitido asegurar la independencia del sector público frente al poder gubernamental, si bien también hay posturas criticando el partidismo del CSA, evidenciado en el hecho de que su composición, al igual que su nombre, cambió tres veces en cinco años, desde su creación en 1982 y, sin embargo, sigue siendo el organismo encargado de velar por el pluralismo y de conceder emisoras.

Un órgano que, a pesar de todo, en España tan siquiera pudo cambiar de nombre ni modificar su composición, porque, entre otros aspectos, no existe.

En el caso de Francia, también se habla de un abandono gradual de valores por parte de la TV pública, como un producto de los movimientos políticos e ideológicos, ligados notablemente al colapso interno de la televisión pública, y que ha provocado que el consenso sólo fuese parcial.

Aún así, lo cierto es que en Francia no se perciben problemas de identidad nacional o lingüística que merezcan ser tratados por los medios de comunicación públicos. ${ }^{34}$

34 Cfr. MORANGE, Jean, "La televisión pública en Francia", en GONZÁLEZ ENCINAR, J.J. (Ed.); 1996: La Televisión Pública en la Unión Europea, op.cit. pp.129-151. 


\section{Reino Unido}

En el Reino Unido, los medios audiovisuales se configuran como un servicio público y son controlados por el Parlamento. Existen tres organismos estatales (la British Broadcasting Corporation, BBC, la Independent Television Commision, ITC, y la Radio Authority) que actúan conforme a los requisitos y objetivos generales definidos por el Parlamento, aunque son independientes en el funcionamiento cotidiano.

Los órganos de control de la BBC son el Consejo Rector, formado por doce gobernadores, incluyendo un miembro nacional para Escocia, Gales e Irlanda del Norte (en RTVE, por ejemplo, no hay miembros regionales y el órgano rector de la CRTVG es unipersonal), además de los Consejos Nacionales de Difusión para Escocia, Gales e Irlanda del Norte, que regulan la política y el contenido de los programas de radio y TV destinados, principalmente, a sus respectivos territorios.

También se han constituido Consejos Asesores Locales de Radiodifusión, representativos de sus colectividades respectivas, que tienen como misión el asesoramiento sobre el funcionamiento y actuación de las emisiones locales de la BBC.

Por su parte, la ITC ha establecido consejos o comités asesores sobre distintas materias, incluyendo un total de diez consejos consultivos de telespectadores regionales.

La descripción de este sistema de órganos de los medios de comunicación constituyen en el Reino Unido una parte de las administraciones independientes del derecho británico, denominados "quangos" (cuasi-autonomous no governmental organizations). Se confía estos órganos al prestigio profesional de sus miembros, si bien éstos son nombrados y destituidos por el Ejecutivo.

Sin embargo, la responsabilidad ministerial de estos órganos está atenuada ya que el ministro responsable sólo responde ante el Parlamento de las grandes opciones y por el presupuesto que depende de su autoridad. Además, el Parlamento está escasamente interesado en el control minucioso de estas instituciones, a diferencia de lo que ocurre en algunos de los otros países analizados.

Con respecto al Reino Unido, Rodríguez García ${ }^{35}$ concluye que los órganos de la $\mathrm{BBC}$ se basan en el prestigio profesional de sus miembros, aunque nombrados por el Gobierno, con lo que se pretende alcanzar mayor objetividad, imparcialidad y neutralidad.

Un sistema que -afirma- ha sido seguido en España por el Consejo de Administración de RTVE, si bien en este último caso "la elección se realiza utilizando como criterio la vinculación política con un determinado partido político, en vez de ver si la persona nombrada reúne las características de independencia y profesionalidad requeridas".

35 Op.cit. 
La BBC fue establecida por una "Royal Charter" (Carta Real) sin legislación que la regulase, por lo que su marco legal ha sido hasta ahora solamente eso, un marco, si bien el tratamiento del tema se ha venido caracterizando por una considerable discrecionalidad, tanto de los reguladores como de los gestores a los que se le había confiado. ${ }^{36}$

Al mismo tiempo, la BBC presenta las características del servicio público televisivo en cuanto a universalidad (contenido de programas para todos los gustos y audiencias), responsabilidad cultural (información y educación, además de entretenimiento), además del principio de independencia frente a la política y al Gobierno.

De hecho, el denominado "comité Grawford" hizo una primera advertencia sobre el enfoque excesivamente intelectual de la programación, pero la calidad de los contenidos y su valor educativo, así como la mucha atención que la BBC dedicaba a la música, merecieron un juicio muy positivo. Aquel comité informó, también, que esto exigía emitir una programación dentro de la cual "la audiencia pudiera elegir el mejor modo de aumentar sus experiencias valiosas y la manera de ampliar y profundizar sus gustos y aficiones".

Así, se entiende que una parte importante de la televisión debe representar un conjunto coherente de valores que permita al Reino Unido verse a sí mismo como una comunidad, una sociedad y una forma de Estado. La televisión se ve como el foro principal que permite a la nación comunicarse con ella misma. Por esa razón, tal y como indican algunos estudiosos del fenómeno televisivo en este país, la televisión británica ha de ofrecer un servicio que englobe todas las circunstancias e intereses significativos de la sociedad, incluyendo la articulación de la conciencia, perspectiva e identidad regional y de las minorías, de forma que el servicio público de la televisión deberá facilitar la participación democrática en una sociedad pluralista, cosa que, dicho sea de paso, tampoco ha garantizado hasta ahora RTVE.

La BBC nació como una solución cooperativa al problema con un accionariado restringido a los fabricantes británicos de aparatos receptores de radio y con el objetivo de generar la suficiente programación para crear un mercado que impulsase la venta de los equipos y así fue como surgió la imposición del canon.

También se prefirió utilizar el procedimiento de la Carta Real, alegando que permitiría a la $\mathrm{BBC}$ mayor libertad de movimientos que si se la sometía al régimen de sociedades vigente. La BBC es una Corporación compuesta por doce miembros, los Gobernadores, nombrados por la Reina en Consejo (en realidad por el Primer Ministro) por un período de cinco años. Al mismo tiempo, también hay un miembro designado en representación de Escocia, otro de Gales y otro de Irlanda del Norte.

36 GIBBONS, Thomas, "La televisión pública en el Reino Unido”, en GONZÁLEZ ENCINAR, JJ. (Ed.); 1996, op.cit. pp. 27-57. 
Los gobernadores son legalmente los responsables de asegurar que se cumplan los objetivos establecidos en la Carta, y aunque la relación entre los Gobernadores de la BBC y sus ejecutivos se ha caracterizado siempre por la ambigüedad, el reciente "White Paper" propone que el papel del gobernador como representante del interés público debe ser más explícito, que velen por el interés público.

Tampoco la relación de la BBC con el Gobierno ha estado claramente definida, lo que muchos han denominado como una política de acomodación, de acuerdo con la cual, ciertos sobreentendidos entre políticos y gestores de la televisión han contribuido, según algunos analistas, a asegurar la independencia de ésta a cambio de limitar la información a lo que resulta políticamente aceptable, si bien la BBC puede oponer protesta pública a cualquier tipo de presión que el Gobierno intente ejercer sobre ella.

Y a cambio de la concesión de la "Licence and Agreement", la BBC también se compromete a ofrecer una programación que se reciba en todas las islas. La cláusula 12 de la Licence prohíbe la financiación por publicidad, lo cual creó un duopolio, de modo que la BBC y la televisión privada disfrutan de fuentes de financiación distintas, lo cual les permite vivir sin necesidad de competir directamente la una con la otra.

En el caso de la BBC, el canon también se justificó para no entorpecer sus objetivos con consideraciones comerciales, lo cual podría provocar una disminución de la calidad de los programas. Incluso se estudió financiación por impuestos, como de hecho ocurre en Italia, pero se desaconsejó porque afectaría a la independencia de la BBC, ya que traería consigo una supervisión por parte del Parlamento.

De hecho, el sistema de canon se ve como un amortiguador constitucional entre los gestores de la televisión y los políticos, si bien la BBC solicitó del Gobierno la ampliación del canon, lo cual ya hace inseparable el argumento político.

\section{E. Países Bajos}

En el sistema holandés, el usuario, a través del derecho de acceso, se convierte en difusor. Es decir, que cualquier ciudadano puede, en principio, ejercer su derecho a emitir asociándose con otros al propiciar la creación de una asociación difusora o inscribiéndose en una ya creada que tendrá mayor tiempo de emisión en función del número de asociados. El Instituto Holandés para la Difusión de Programas (NOS) establece un foro para la cooperación entre las distintas asociaciones u organizaciones difusoras y las asociaciones difusoras-aspirantes que hayan obtenido tiempo de transmisión o emisión. Su papel como proveedor y realizador de programas es doble. En primer lugar, para satisfacer necesidades de carácter social, cultural, religioso, espiritual e ideológico y que no se vean cubiertas en grado suficiente por los programas que emiten las distintas emisoras de 
radio y televisión. La NOS se estructura a través del Consejo Directivo, compuesto por un presidente y un miembro por cada una de las asociaciones u organizaciones difusoras, más cuatro miembros designados por el Ministro de Cultura.

Asimismo, dispone, como órgano consultivo, de un Consejo de Programación, compuesto también por un miembro por cada una de las asociaciones u organizaciones difusoras y por un número igual de representantes de instituciones culturales nombrados por el Ministro de Cultura.

Con respecto a los medios de radio y televisión municipales y regionales, existe un Consejo de Programas constituido por los movimientos sociales, culturales, religiosos e ideológicos que funcionan en las provincias y municipios.

Todo el sistema audiovisual holandés establece como principio fundamental el derecho de acceso de todas las tendencias sociales, que puede convertir al ciudadano en difusor y no como un mero receptor pasivo de la información manipulada. Existe, por lo tanto, una relación directamente proporcional entre derecho de acceso y el control de los medios de comunicación, de forma que cuanto más se reconoce este derecho de acceso, menos es el control que se establece sobre los medios de comunicación porque menos necesario es. Se trata de una correspondencia biunívoca y de un sistema que podría ser utilizado en nuestro ordenamiento jurídico para el reparto de tiempo de emisión en relación al derecho de acceso que se debería otorgar a los distintos grupos sociales y políticos, garantizando, en definitiva, la autoafirmación de la conciencia individual y colectiva $^{37}$.

Sin embargo, no se puede entender el sistema televisivo holandés sin antes hacer referencia a su historia y al principio básico de "columnización" de su sociedad, de acuerdo con el cual la estructura social se estratificaba de manera vertical según líneas de agrupaciones o comunidades, y no de manera horizontal, por clase social u ocupación ${ }^{38}$.

El tiempo de transmisión se dividió según la proporción del número de miembros de cada asociación. También la aplicación de normas se dejó, en gran parte, en manos de las distintas asociaciones de televisión y el sistema quedó estructurado para que garantizase que un perjuicio desde una perspectiva sería equilibrado por un perjuicio opuesto.

El NOS, que posee el veinte por ciento del tiempo de transmisión, tiene como misión satisfacer las necesidades que tengan poca probabilidad o dificultad de ser satisfechas por otras organizaciones. Y aunque tampoco existe, en este caso, una normativa formal para la política editorial y de programación del NOS, su

37 RODRÍGUEZ GARCÍA. Op.cit.

38 McQUAIL, Denis, "Los Países Bajos: libertad y diversidad bajo condiciones de variedad de canales", en BLUMLER, G.J.; 1993, op.cit. pp. 131-148. 
estructura, su meta y su tradición, lo llevan a suministrar una cobertura de noticias muy imparcial y neutral ${ }^{39}$.

El sistema hace una valoración amplia y general de los principios de pluralidad y diversidad de contenidos, una amplitud que se establece gracias a la disposición que permite que los nuevos canales soliciten una parte del tiempo de emisión siempre que demuestren que disponen, entre otros requisitos, de un número mínimo de miembros. Mientras que el principio de la universalidad de contenidos se consigue, gracias a una cláusula que, además, obliga a que cada una de las principales asociaciones provean de un abanico completo de programación distribuido en el tiempo de transmisión asignado.

\section{F. Suiza}

Suiza dispone de un área de 41 mil kilómetros y con menos de siete millones de habitantes, de los que más de un millón son extranjeros, además de una sociedad plurilingüe (alemán, francés, italiano) y con un sistema político altamente diferenciado y excepcionalmente exigente, pues está constituido como una democracia directa, con alto grado de segmentación cultural, y que requiere de instituciones políticas y de medios altamente eficientes y diferenciados.

Por eso, aparte de la influencia que puedan tener los partidos políticos, también hay que tener en cuenta la representación de intereses económicos, culturales, así como las organizaciones de medios y de ciudadanos de los que dependen los políticos.

El resultado es una mezcla dispar de intereses políticos, económicos y culturales, que los grupos distintos ven respetados por la programación de acuerdo a sus opiniones y creencias, lo cual provoca que la coherencia de este sistema de organización de la televisión sea relativamente frágil, ante la dificultad para crear consenso entre los diversos agentes.

Y aunque el potencial estructurador de la política televisiva de Suiza es también relativamente alto, ocurre, sin embargo, que su capacidad de manejo del medio es ínfima, lo cual demuestra la dificultad que entraña el establecimiento de sistemas de control normativo que protejan todos los valores propios de su diversidad cultura ${ }^{40}$. Un ejemplo, el suizo, que también podría tomarse como referencia para arbitrar en España un sistema acorde, también, con su diversidad.

\section{La búsqueda de legitimación social}

Algunos autores señalan que el nuevo criterio que parece distinguir a algunas de las más importantes televisiones públicas europeas es que su desarrollo

39 Ibidem.

40 SAXER, Ulrich, "La televisión en una pequeña sociedad multicultural: el caso de Suiza", en BLUMLER, G.J.; 1993, op.cit. pp. 171-190. 
ya no depende directamente de decisiones políticas, sino de una política industrial y de objetivos económicos, que ha encontrado su máxima expresión en EE.UU., donde la TV privada domina el sector de forma abrumadora y la libertad de prensa se identifica con la libertad de empresa, equiparando la libre circulación de ideas a la de mercancías.

En este sentido, Sampedro Blanco indica que "la explicación culturalista no puede dar cuenta del sistema de radiodifusión germano, altamente federalizado, en oposición al centralismo que exhibe el sistema galo", pues "Iparralde, Alsacia, Córcega o la Bretaña mantienen una distancia lingüístico-cultural mucho más profunda, entre sí y con respecto a París, de la existente en cualquier grupo de Lander alemanes". ${ }^{41}$ Por otra parte, este autor sostiene también que "parece claro que en el Estado español no fueron las peculiaridades culturales o idiomáticas las que aconsejaron la creación, por ejemplo, de TeleMadrid".

Sin embargo, todos parecen coincidir en que la noción de servicio público ha de considerarse con criterios constitucionalistas y bajo la disciplina del Derecho, ante las relaciones cada vez más conflictivas con el poder político y la pérdida de consenso a la hora de establecer mecanismos que aseguren un control democrático de las televisiones públicas. Y también se está demostrando que el aumento de canales, lejos de favorecer la autonomía y diversidad, produce mayor dependencia y homogeneización y una desvirtuada confusión de lo público con lo estatal o gubernamental, por lo que se cree imprescindible resituar la TV dentro de una perspectiva más amplia de gestión y más dimensiones que la del control partidista, convirtiéndose en representativa y dinamizadora de los distintos sectores sociales.

Jay G. Blumler, al analizar las nuevas fronteras para la televisión pública, recuerda que en las sociedades multiculturales (y la española puede considerarse como tal), también son necesarios los esfuerzos de apoyo a la diversidad linguiística y el mantenimiento de la funcionalidad del idioma como portador de la identidad cultural. ${ }^{42}$

De hecho, podría darse mayor prioridad a buscar y otorgar acceso a los elementos marginales y a las voces menores de las sociedad, sin caer siempre en los puntos de vista de los grandes partidos y corrientes principales.

En este sentido, la televisión debería tener una función de socialización, de "servir como fiducitaria para espolear la curiosidad de una sociedad siempre cambiante" 43 , considerando que la televisión pública es especialmente significativa para los procesos de cambio e integración social y para que la discusión de asuntos no sea monopolizada por las elites, pues la libertad de medios no es un valor absoluto, sino que debe tener en cuenta numerosas consecuencias sociales.

41 SAMPEDRO BLANCO, V.; 1996: “Televisións rexionais: cadeas políticas”, en revista A Trabe de Ouro, $\mathrm{n}^{\circ} 27$.

42 BLUMLER, G.J.; 1993: Televisión e interés público. Bosch, Barcelona.

43 Ibidem. 
$\mathrm{Y}$ aunque se trata de un producto marcadamente orientado al consumidor, la programación televisiva difiere mucho de otros productos, y cita Blumler, a modo de ejemplo, coches, tostadoras y lavadoras, para afirmar que mientras que estos últimos proporcionan los medios, el primero configura y modifica los significados ${ }^{44}$.

Una consideración que, en el caso español, no parece que fuese tenida en cuenta por el legislador, pues, como se ha indicado anteriormente, éste contempló los medios audiovisuales bajo una perspectiva exclusivamente técnica, como simples "aparatos" de difusión o "fabricación", casi se podría decir, de imágenes y voces.

También otros autores consideran, en el mismo sentido, la necesidad de contar con la perspectiva de aquellos grupos de la sociedad que podrían verse afectados significativamente por las políticas adoptadas, pero que no tienen un interés creado lo suficientemente bien organizado, en términos financieros, como para lograr una representación para asegurar que en el balance final de intereses que subyace a la mayoría de las decisiones políticas, la consideración de los intereses de segmentos importantes del público no sea omitida.

Pero la mayoría de los canales europeos están imbuidos de vocación cultural, pues en Europa la televisión fue originariamente contemplada como una empresa enteramente cultural, como parte del sector de la sociedad responsable de generar y difundir su propia riqueza lingüística, espiritual, estética y étnica.

Así se recuerda que, en más de una ocasión, algún presidente francés ha llamado a su servicio de televisión como "la voz de Francia". Se pensaba en la televisión como fuerza socialmente integradora, centrípeta, que, en palabras de Katz, ofrecía la oportunidad de la experiencia compartida, que contribuye a la autenticidad, al conectar a la sociedad con su centro cultural y permitir que los diversos segmentos de la sociedad se familiaricen unos con otros.

Alasdair Milnes, director general de la BBC durante la década de los ochenta, dijo que la televisión pública "debe hacer que lo popular sea valioso y que lo valioso se haga popular".

Sin embargo, como se ha visto, esto no implica que la dicotomía control/ independencia haya sido organizada sobre ejes idénticos en toda Europa. Pero aún así, los entes públicos nacionales encontraron fuerza "en las profundas raíces que echaron en el seno de sus estructuras sociales" y el pluralismo, de múltiples tipos (regional, lingüístico, político, cultural), fue la imagen de marca de las televisiones públicas en la Europa Occidental, cosa que no se puede decir, por ejemplo, de los centros territoriales de RTVE ni tampoco de la mayor parte de las televisiones autonómicas, regidas por el mismo patrón organizativo.

44 Ibidem. 
"Si la sociedad es diversa en su composición, es natural que cada uno de sus sectores pueda encontrar en la programación televisiva materiales que reflejen sus intereses y con los que se pueda identificar", sostiene Blumler, aludiendo también a la insistencia en la necesidad de fortalecer el papel de la televisión como vínculo social "en el seno" de una comunidad.

Como también hay quienes incluso se refieren a las garantías que ofrece el denominado principio de cooperación informal, por el cual los organismos de supervisión suelen preferir resolver los conflictos por medios informales, en vez de tener que recurrir a sus poderes formales, y cuyas herramientas pueden variar, desde el amistoso "tirón de orejas", a informar al público y amenazar con la imposición de sanciones oficiales.

Pero hay una función básica de la televisión pública que, por ejemplo, la jurisprudencia constitucional alemana no pudo ignorar, y es que la televisión pública es un instrumento básico de vertebración de la comunidad y que las decisiones fundamentales se relacionan no sólo con la programación, sino primariamente con el ámbito territorial y la lengua o lenguas de emisión. Y junto o en la base del mercado de las ideas, también está lo que se ha definido como el "mercado para las lealtades", en el que compiten quienes pugnan por conservar o alcanzar el poder y por las señas de identidad que definen las fronteras.

Un mercado en el que se vende identidad nacional y en el que los consumidores compran "lealtad", "ciudadanía" o "identidad", entendidas como sentimientos compartidos de pertenencia a un grupo lingüístico, nacional o étnico.

Sirva también como referencia, en este sentido, la resolución de la Cuarta Conferencia Ministerial europea sobre la política de comunicaciones de masas, celebrada en Praga el 7 y 8 de diciembre de 1994, en el marco del Consejo de Europa, en la que ya se indicaba, por aquel entonces, que las televisiones de servicio público debían desarrollar una programación pluralista y emitir programas que interesen a un público amplio, sin perjuicio de permanecer atentos a los deseos de los grupos minoritarios.

\section{Bibliografía citada y consultada:}

- AA.VV.; 1999: Jornadas de Consejos Asesores de RTVE. Parlamento de Andalucía, Sevilla.

- AA.VV.; 1995: El régimen jurídico de la televisión. Centro de Estudios Constitucionales, Colección "Cuadernos y Debates", nº 55, Madrid.

- AA.VV.; 1984: Jornadas sobre Televisión Autonómica. Diputación General de Aragón.

- BASTIDA, F.J.; 1987: "Las televisiones regionales en España", en revista Autonomies, $\mathrm{n}^{\mathrm{o}} 7$. 
- BLUMLER, G. J.; 1993: Televisión e interés público. Bosch, Barcelona.

- CHAMOUX; 1994: Droit de la communication. P.U.F., París.

- CHINCHILla MARTíN, C., 1987: "Las competencias de las Comunidades Autónomas en materia de televisión", en revista Autonomies, n 8 .

- CHINCHILlA MARTÍN, C. (Ed.); 1988: Legislación básica de radio y televisión. Tecnos, Madrid.

- DE LA QUADRA-SALCEDO, T.; 1976: El servicio público de la televisión. Instituto de Estudios Administrativos, Madrid.

- DE LA QUADRA-SALCEDO, T.; 1997: "Los servicios televisivos", en Malaret García (Dir.), "Régimen jurídico de los servicios públicos", en Cuadernos de Derecho Judicial, Madrid.

- DE ESTEBAN, J.; 1997: "Los medios de comunicación como control del poder político", en Revista de Derecho Político, no. 42.

- FERNÁNDEZ, E.; 1996: "Medios de comunicación: ¿sustitutos de la actividad política?", en revista Contribuciones, $\mathrm{n}^{\circ} .2$.

- GARCÍA LLOVET, E.; 1991: El régimen jurídico de la radiodifusión. Marcial Pons, Madrid.

- GAY FUENTES, C.; 1994: La Televisión ante el Derecho Internacional y Comunitario. Marcial Pons, Madrid.

- GODOY, A.; 1995: El derecho de la Televisión sin Fronteras. Aguaclara, Alicante.

- GONZÁLEZ ENCINAR, J.J. (Ed.); 1996: La televisión pública en la Unión Europea. McGraw-Hill, Monografía "Ciencias Jurídicas", Madrid.

- GONZÁLEZ PASCUAL, M.I.; 1999: "Las Televisiones Autonómicas, la historia de un desatino", en Revista Vasca de Administración Pública, nº 55.

- HIERRO, J.L.; 2000: "La evolución normativa", en Televisión y desarrollo. Las Regiones en la Era Digital. Consejería de Educación de Extremadura.

- MANEIRO VILA, A./ CABALEIRO DURÁN, A.; 1993: A TVG, unha institución pública imprescindible en Galicia. Edicións Lea, Santiago de Compostela.

- NAVARRO DE LUJÁN, V.L.; 1997: "El modelo de televisión autonómica", en Revista Valenciana D' Estudis Autonómics. No 19.

- RODRÍGUEZ GARCÍA, J.A.; 1998: El control de los medios de comunicación. Dykinson, Madrid.

- SALA ARQUER, J.M.; 1984: "El Estado neutral. Contribución al estudio de las administraciones independientes", en Revista Española de Derecho Administrativo, $\mathrm{n}^{\circ} 42$.

- SAMPEDRO BLANCO, V.; 1996: "Televisións rexionais: cadeas políticas”, en Revista A Trabe de Ouro, no 27.

- SAUVY, A.; 1962: La naturaleza social, Taurus, Madrid. 